\title{
Análisis de las competencias informacionales en la comunidad académica del CICIMAR-IPN
}

\author{
Teresa de Jesús Barriga Ramírez \\ José Luis Ortíz Galindo \\ Laura Margarita Pérez Rojas \\ Instituto Politécnico Nacional, Centro Interdisciplinario de Ciencias Marinas - CICIMAR-IPN, México
}

\author{
Bárbara Susana Sánchez Vignau \\ Universidad de la Habana, Dirección de Información Científica y Técnica - DICT, Cuba
}

CASE REPORTS

\begin{abstract}
Resumen
Objetivo. Caracterizar la competencias informacionales de la comunidad académica y los bibliotecarios del CICIMAR-IPN. Métodos. Se aplicó una encuesta la cual fue complementada con entrevistas a los directivos y coordinadores de los programas de posgrado del centro. Resultados. Se identificaron diversas falencias en la comunidad, como: la necesidad de fomento del uso de las tecnologías de información y comunicación entre los docentes e investigadores; la difusión y reconocimiento de las normas de propiedad intelectual entre los estudiantes; y el desarrollo de competencias directivas y pedagógicas para la transmitisión de conocimientos entre los bibliotecarios. Conclusiones. Se evidencia la necesidad de crear un programa de alfabetización informacional para la comunidad académica del CICIMAR-IPN, que contribuya a la generación y transferencia de conocimientos para promover su excelencia.
\end{abstract}

Palabras clave

Alfabetización informacional ; Habilidades informativas ; Competencias informacionales ; Gestión de la información ; Gestión del conocimiento ; Centro Interdisciplinario de Ciencias Marinas ; México

\section{Information literacy analysis in the scholar community of CICIMAR-IPN}

\section{Abstract}

Objective. Determine the competences and skills in management of information of the scholar community CICIMAR-IPN.

Methods. A survey was conducted. This was supplemented by interviews for managers and coordinators of the graduate programs of the center. Results. We identified several needs in the community, such as promoting the use of information technologies and communication between teachers and researchers; dissemination and recognition of intellectual property rules among students; and skills development for transmitisión knowledge among librarians. Conclusions. There is a need to develop an information literacy program for the scholar community CICIMAR-IPN, which contributes to the generation and transfer of knowledge to promote excellence.

\section{Keywords}

Information literacy ; Information skills ; Information competencies ; Information management ; Knowledge management ; Centro Interdisciplinario de Ciencias Marinas ; Mexico 


\section{Introducción}

Actualmente el Centro Interdisciplinario de Ciencias Marinas dependiente del IPN (CICIMAR-IPN), transita hacia el nuevo modelo educativo, centrado en el aprendizaje del estudiante, encaminado a la formación de individuos altamente calificados para el ejercicio profesional de las Ciencias Marinas y temas afines, pero también con el compromiso de generar conocimientos útiles para el desarrollo de la sociedad; de ahí la necesidad de articular información, comunicación y conocimiento a través de un enfoque de alfabetización informacional (ALFIN).

La función de las bibliotecas como parte de la infraestructura de apoyo académico, contribuyen al logro de la misión de las IES, en muchas de ellas se han logrado modernizar, gracias a que han sorteado una serie de dificultades, en cuanto a instalaciones adecuadas, colecciones vigentes, servicios actualizados, equipos y TIC, para hacer frente a los programas de desarrollo universitario que se debe impulsar con el nuevo modelo educativo, centrado en el aprendizaje del estudiante.

Con esa lógica, los bibliotecarios y profesionales de la información que pretenden impartir o coordinar el esfuerzo de Alfabetización Informacional deben poseer competencias personales, profesionales, informativas y docentes que incluyan: conocimientos; habilidades y destrezas; y aptitudes y valores, tal como lo indican las normas sobre competencias y habilidades de la Association of Collegue and Research Libraries (ACRL): Competencias para evaluar y calificar; de comunicación, conocimiento curricular, para integración de la Alfabetización Informacional en la vida académica; para el diseño educativo; de liderazgo; para la planificación; para la promoción y marketing; para enseñar y conocimiento de los temas y materias disciplinares concretas.

Referente a las competencias de los estudiantes de posgrado, el trabajo de Valdés Cuervo, Ver a Noriega \& Martínez (2012), señalan que las competencias científicas son parte esencial de la formación del posgrado y las clasificaron en: Competencias genéricas; Gestión de recursos para la investigación; y Generación y divulgación del conocimiento.

En México desde 1995, se iniciaron las acciones en materia de educación para usuarios por parte de la Universidad Autónoma de Ciudad Juárez (UACJ), quién la incluye como tema del Primer Encuentro Internacional sobre Desarrollo de Habilidades Informativas y en el cual se elabora la "Declaratoria sobre Desarrollo de Habilidades Informativas (DHI) en Instituciones de Educación Superior de México", documento que significó un paso muy importante en la consolidación de programas de educación de usuarios en todo el país. El Segundo Encuentro de DHI, se realizó en el año 2000 y abordo la Instrucción de usuarios ante los nuevos modelos educativos, el autoaprendizaje de alumnos y maestros, lográndose la "Declaratoria de la Función de la Biblioteca en Modelos Educativos Orientados al Aprendizaje". En el Tercer Encuentro DHI en 2002, se abordó la temática sobre las normas de la alfabetización informativa y los asistentes a dicho encuentro, trazaron las Normas sobre Alfabetización Informativa en Educación Superior: declaratoria redactada con propuestas de todos los participantes. Con lo que se inició un nuevo ciclo para las bibliotecas académicas de formar egresados con competencias informativas. En el Cuarto Encuentro DHI en 2004, la puesta en servicio de una lista de discusión sobre el tema, la página web con recursos de utilidad para los interesados y el Foro Nacional sobre DHI, incorporó a más bibliotecarios interesados en la temática. Así que, durante el Quinto Encuentro DHI, ya se compartieron experiencias, ideas y proyectos; y se hizo énfasis en los temas de evaluación y diagnóstico de competencias y de programas en materia de Alfabetización Informativa. A la fecha, se han organizado siete encuentros DHI, el último se celebró en 2011 y se cerro el ciclo.

Por parte de la Dirección de Bibliotecas de la Universidad Veracruzana, se promueve el Coloquio Administración y Liderazgo en el Campo Informativo (ALCI). A la fecha se han llevado a cabo diez coloquios. Además, se ha logrado consolidar un programa con talleres independientes, cursos curriculares (Competencias Informativas para el Aprendizaje) y cursos para docentes.

El Instituto de Investigaciones Bibliotecológicas y de la Información de la UNAM (IIBI-UNAM), es otra institución que en la actualidad realiza investigaciones para integrar información básica que de sustento a investigaciones aplicadas en ALFIN.

El Colegio de México, A.C. desde 1996, a través del cuerpo académico, bibliotecas, información y sociedad, realiza investigaciones para la construcción de indicadores sociales para identificar, sistematizar y evaluar las fuentes de información relevantes con respecto a las TIC en las IES.

La Dirección General de Bibliotecas de la UNAM, difunde un programa de actualización profesional, que incluye talleres de "Coaching en las bibliotecas" y "Actualización de técnicas grupales para instructores". Así como talleres dirigidos a usuarios con la finalidad de desarrollar habilidades informativas a solicitud.

La Red de Bibliotecas y el Sistema de Educación Media Superior de la Universidad de Guadalajara promueve el Diplomado en Competencias Docentes y el de Inducción al Bachillerato General por Competencias.

Los Centros Públicos de Investigación dependientes del Consejo Nacional de Ciencia y Tecnología (CONACYT), han iniciado un diagnóstico que les permitirá desarrollar un programa de Formación de Usuarios en el futuro.

En el caso del Instituto Politécnico Nacional, en 2004 se creó el Centro de Formación e Innovación Educativa (CFIE), para atender los requerimientos de formación, actualización y capacitación, para contar con el personal que cumpla con los perfiles que requieren los modelos Educativo y de Integración Social. Este Centro a través de Programas de 
Formación y Desarrollo Profesional, brinda cursos, diplomados y seminarios a Docentes, Cuerpos Directivos y Personal de Apoyo. No obstante, carece de ofertas específicas de fomento de competencias informacionales. Desde la Dirección de Bibliotecas no existen acciones con respecto a ALFIN, una de las acciones adyacentes más próxima compete al "Seminario Repensar la Comunicación", coordinado desde 2006 por el M. en C. Noel Ángulo Marcial, del Centro de Investigaciones Económicas, Administrativas y Sociales (CIECAS), en colaboración con la Unidad Politécnica para la Educación Virtual y la Revista Innovación Educativa.

Otra acción, del Instituto Politécnico Nacional corresponde al taller "Gestión de la información para la práctica académica y de investigación”, coordinado desde 2009 por la Profa. Catalina Puente Palazuelos, del Centro Interdisciplinario de Investigaciones para el Desarrollo Integral, Unidad Sinaloa (CIIDIR-Unidad Sinaloa), en colaboración con la Lic. Teresa de Jesús Barriga Ramírez del CICIMAR-IPN, en modalidad mixta, con registro de curso de propósito específico por la Secretaria de Investigación y Posgrado del propio Instituto.

La revisión de las páginas de los Sistemas Bibliotecarios de las IES, afiliadas al Consejo Nacional para Asuntos Bibliotecarios de las Instituciones de Educación Superior, A.C (CONPAB), exteriorizan que ofrecen servicio de Formación de Usuarios y Orientación, sin explicar a que se refiere, hecho que advierte sobre la falta de definición en este tipo de programas, más no de los esfuerzos de un buen número de bibliotecarios que han iniciado acciones prácticas ALFIN, aprovechando hacer lo que se pueda con los recursos que se tengan.

A pesar que existe una falta de cultura en el uso de la información en México, el desarrollo de las bibliotecas debe continuar y los bibliotecarios y profesionales de la información requieren competencias personales, profesionales, informativas y docentes, para llevar a cabo programas de habilidades informativas o ALFIN.

De acuerdo al estado del arte descrito, se carece de las políticas institucionales que permitan el éxito de los planes ALFIN, que se requieren en las distintas IES de México.

En suma, el comportamiento informacional, las competencias y los modelos son componentes básicos a considerar para el diseño de acciones o programas de Alfabetización Informacional que se pretendan proyectar. El presente estudio tomó en cuenta las Directrices Internacionales para la Alfabetización Informativa de la Federación Internacional de Asociaciones e Instituciones Bibliotecarias (IFLA, por sus siglas en inglés), en el sentido que representan un prototipo relativo a las competencias informacionales en estudiantes de nivel superior, además que permiten la inclusión de algunos elementos de otros modelos, fundamental para un proceso evolutivo como lo es ALFIN (Lau, 2004).

\section{Material y métodos}

Inicialmente se utilizó el "modelo de diagnóstico y caracterización" propuesto por Uribe Tirado, Marín, Palacio, Gaviria, Muñoz \& Preciado (2008), configurándose una matriz de recopilación de información para el acopio y análisis de la información requerida para la elaboración de los temas tratados en esta investigación, integrada por fichas de contenido de los autores recopilados, así como fichas de análisis de los proyectos de investigación similares.

En segundo lugar para la selección de la población encuestada se utilizaron tres procesos básicos del modelo "método integral para la determinación y la satisfacción dinámica de las necesidades de formación e información" (AMIGA) de Núñez Paula (2004).

En tercer lugar, se diseñó y aplicó un cuestionario a una muestra estructurada de Docentes-Investigadores, Estudiantes y Personal de la Biblioteca, para conocer las competencias informativas que poseen, indagar sobre la opinión de los servicios y recursos informativos que brinda la biblioteca y examinar el nivel de apropiación de las TIC. La encuesta constó de cuatro secciones: Gestión de Información, Servicios Bibliotecarios, Tecnologías de Información y Comunicación (TIC) y Competencias Informacionales.

También se empleó la herramienta de la entrevista en personas clave: Directora, Subdirectores y Coordinadores de los Programas de Posgrado del CICIMAR-IPN (Maestría en Ciencias en Manejo de Recursos Marinos y el Doctorado en Ciencias Marinas) para analizar las competencias genéricas, de generación y divulgación del conocimiento de los Docentes/Investigadores y Estudiantes, además para saber su criterio sobre la posible función de los bibliotecarios en el fomento de competencias informacionales.

En cuarto lugar, se realizó la sistematización y análisis de la información obtenida a través de la encuesta y la entrevista y los resultados fueron el punto de partida para modelar la propuesta de un plan de acciones en ALFIN.

En cuanto a la etapa inicial de recopilación y análisis de la información para precisar el estado del arte de la Alfabetización Informacional se valoró la "Metodología de análisis y gestión socioeconómica" de Peñalva Rosales (2010) y el "Modelo de diagnóstico y caracterización" de Uribe Tirado et al. (2008). Seleccionado este último en primer lugar, porque se utilizó para un estudio similar en la Universidad de Antioquia, Colombia y porque permite visualizar de forma integral los recursos informativos, herramientas, técnicas y acciones que el investigador puede emplear al iniciar un estudio. Además facilita el ingresar nuevos recursos o descartar de acuerdo con el grado de conocimiento que va adquiriendo el investigador sobre el tema a medida que avanza en el estudio. También favorece el control de los registros de las actividades, recursos, herramientas y técnicas aplicadas durante la investigación. La bibliografía y estudio de casos estudiados para abordar el tema de ALFIN, solo presento un poco 
de dificultad con relación a la escasez de estudios similares en el nivel posgrado, tanto en México como de otros países. La actualidad del tema permitió localizar una gran diversidad de acciones ALFIN en diversos contextos educativos, algunos integrados a los planes y programas educativos, pero también un gran número como acciones independientes.

\section{Resultados}

\subsection{Población encuestada}

Cuando se hizo la selección del tipo de usuarios de la biblioteca que se encuestó, no se contempló ningún inconveniente al precisar los grupos. Se aplicaron: 52 encuestas entre los Docentes/Investigadores de un total de 150, equivalente al 34\%; 62 encuestas a Estudiantes de un total de 114, equivalente al 54\%; y cuatro encuestas entre los bibliotecarios de un total de cinco, equivalente al $80 \%$.

\subsection{Gestión de información}

El valor de la información institucional en el desempeño académico, investigativo y profesional o laboral de los tres grupos de encuestados, se observa en la Fig. 1, que es muy útil (38\% Docentes/Investigadores, 42\% Estudiantes y $100 \%$ Bibliotecarios). En referencia a las vías de comunicación de la información institucional, los resultados fueron contrastantes, ya que en los grupos de Docentes/Investigadores y Estudiantes, seleccionaron el valor (Poco efectivo), que representan el 37 y $24 \%$ respectivamente y solo los bibliotecarios optaron por el valor (Muy efectivo) $100 \%$, como se indica en la Fig. 2.

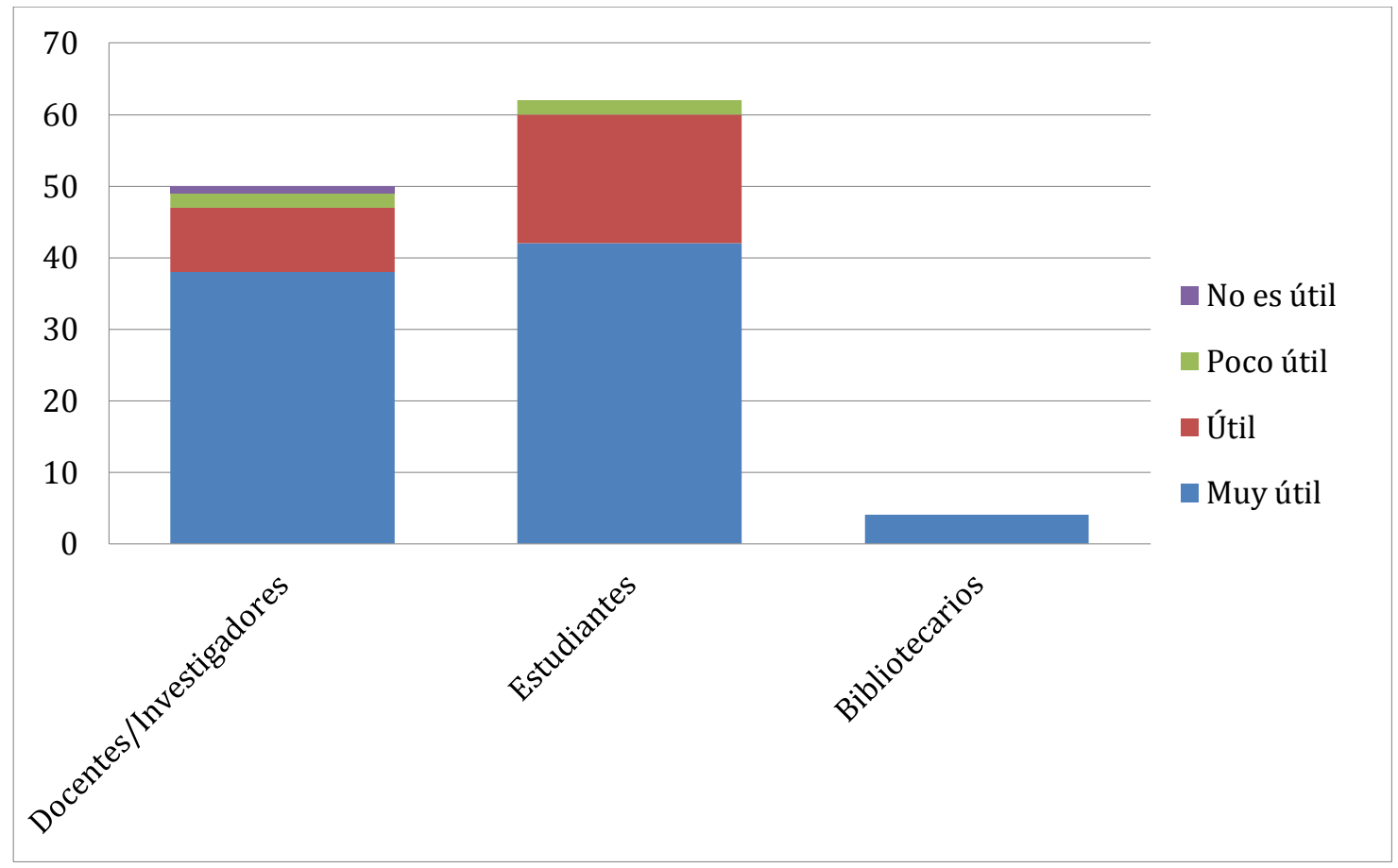

Figura 1 : Valor de la información institucional en el desempeño académico, investigativo y profesional o laboral 


\subsection{Servicios bibliotecarios}

En términos generales, en el componente de horario habitual de asistencia a la biblioteca, predomina una baja asiduidad de usuarios, mismos que se inclinan en asistir antes de las 14:00 horas y mayoritariamente son del grupo de los Estudiantes, así como el hecho de no estar sujeto a ningún horario (35\% y 46\% respectivamente) (Fig. 3).

En la Fig. 4, se aprecia que los cuatro servicios con más demanda por parte de los Docentes/Investigadores y los Estudiantes son: Fotocopiado (20\% y 23\%, respectivamente), Consulta en sala (23\% y $18 \%$, respectivamente), Préstamo a domicilio (19\% y 17\%, respectivamente). El Uso de Cubículos (19\%), tiene mayor demanda en el grupo de los Estudiantes.

De igual manera, en la Fig. 5 se observa que los Docentes/Investigadores y los Estudiantes revelan que el motivo principal de asistencia a la biblioteca es la consulta de libros (50\% y 43\%, respectivamente), en ambos grupos, le siguen las revistas (11\% y $28 \%$, respectivamente), tesis (24\% y $16 \%$, respectivamente) y artículos (15\% y $13 \%$, respectivamente). Además de preferencia por los servicios de Consulta en Sala, Fotocopiado y Préstamo a Domicilio.

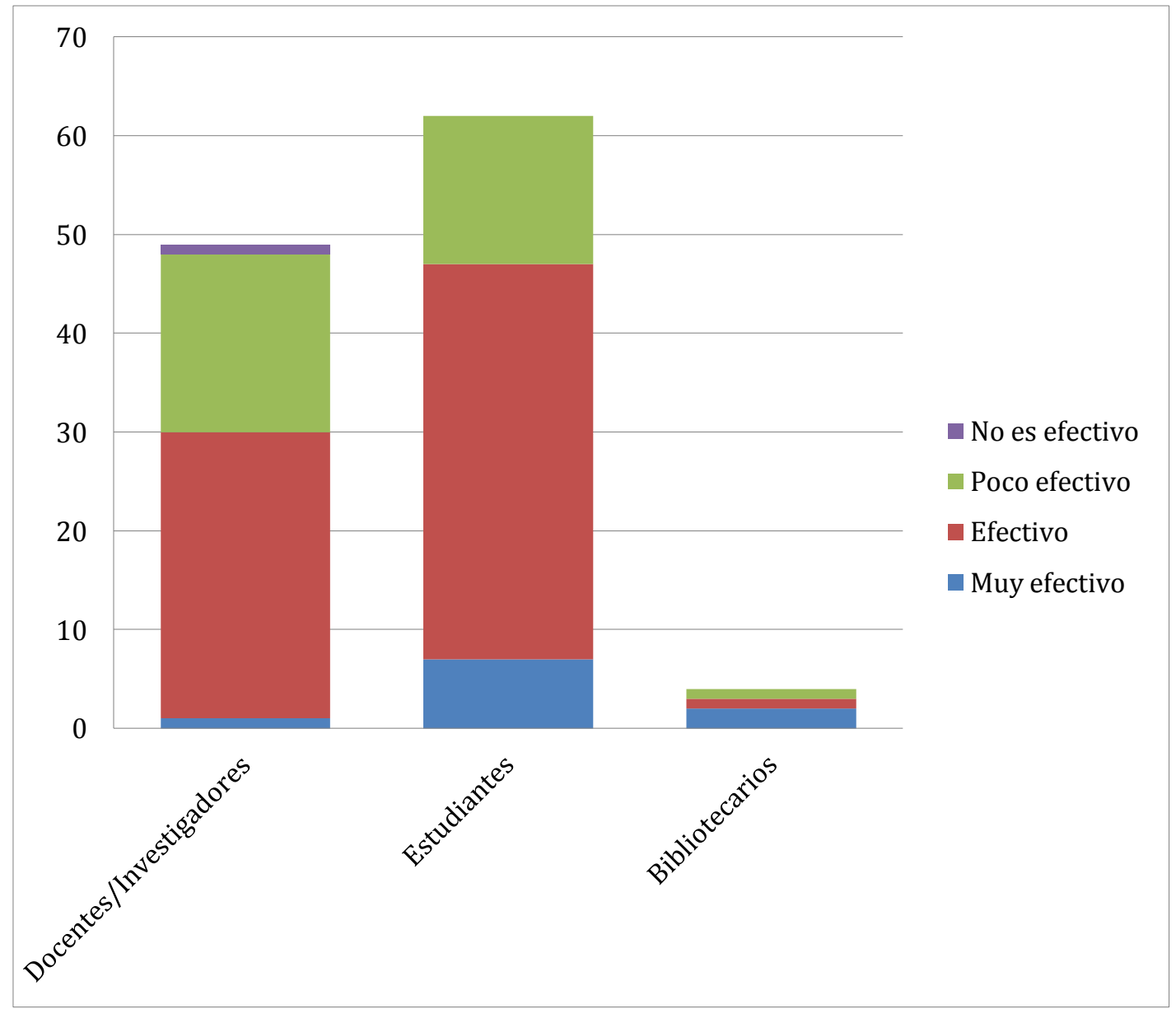

Figura 2 : Vías de comunicación de la información institucional 


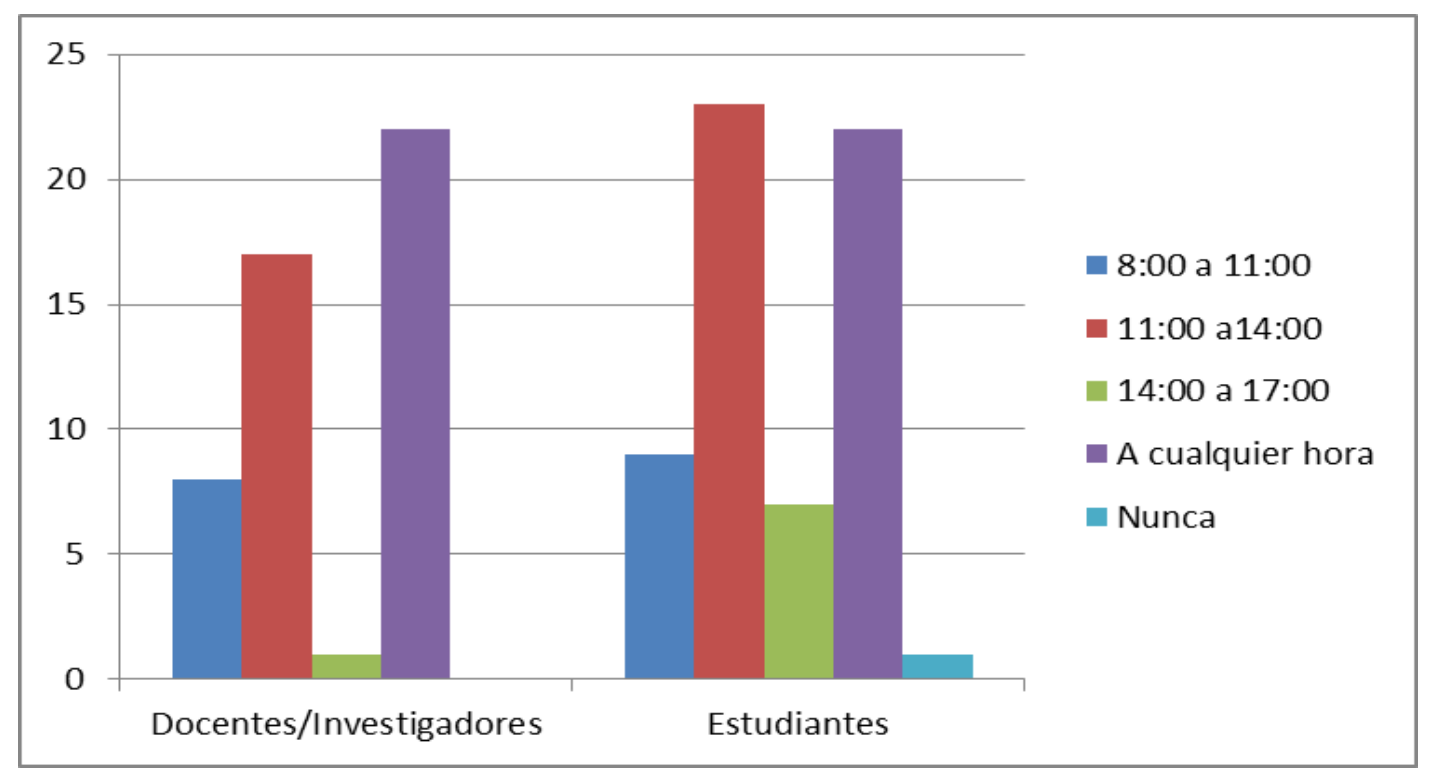

Figura 3 : Horario habitual de asistencia a la biblioteca

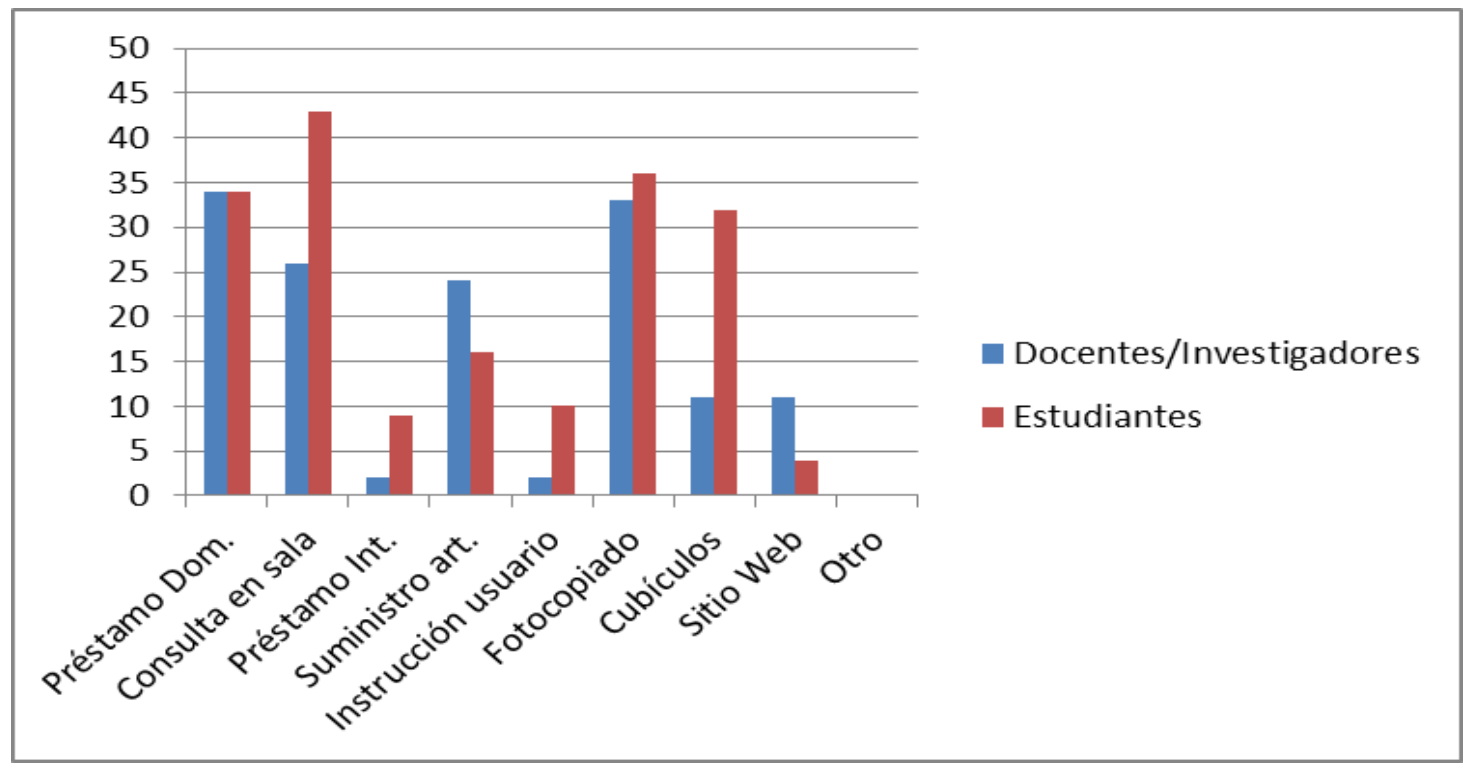

Figura 4 : Servicios utilizados 


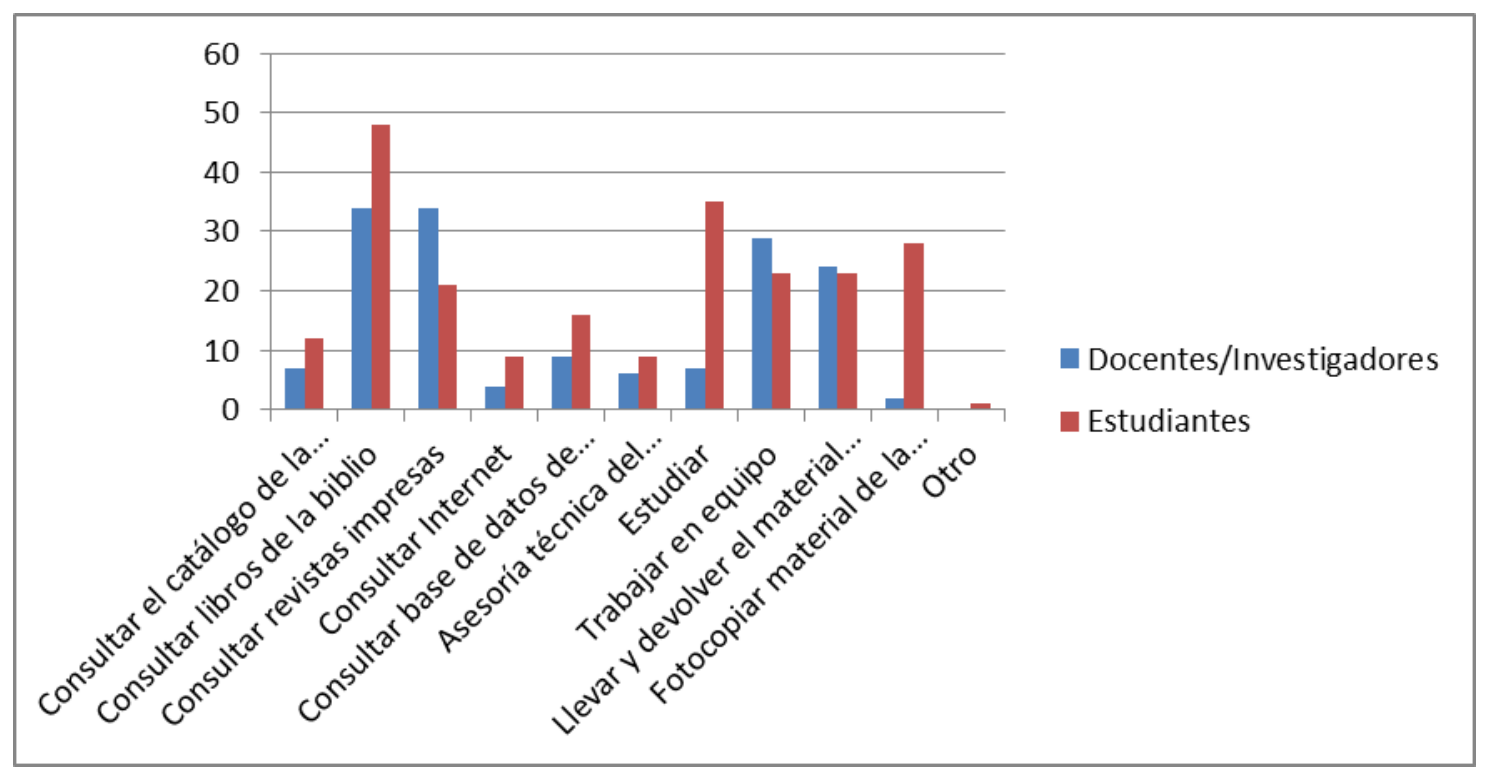

Figura 5 : Motivo de asistencia a la biblioteca

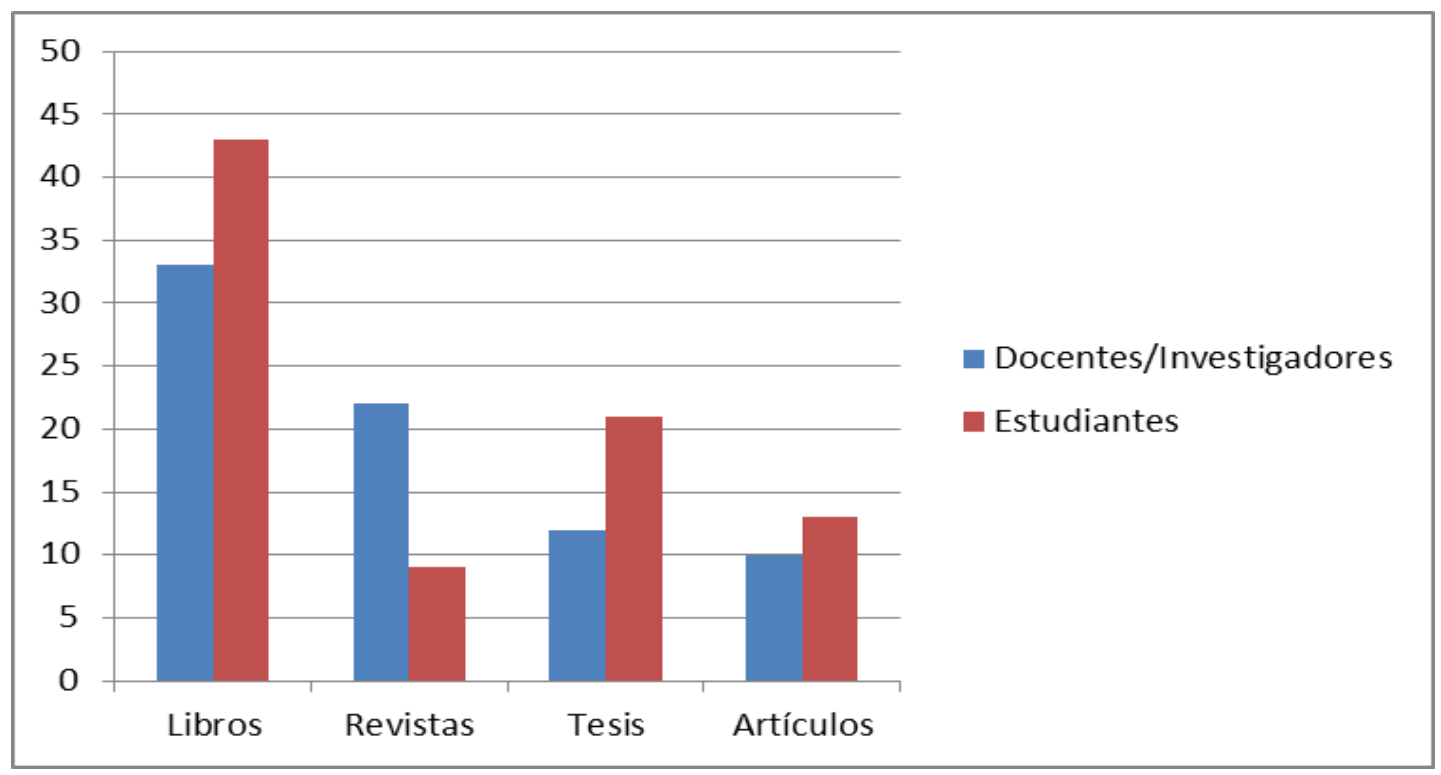

Figura 6 : Colecciones impresas más solicitadas en préstamo

De acuerdo a la Fig. 6, se hace referencia a las colecciones impresas y corresponde a los libros el valor más alto (50\% y $43 \%$, respectivamente), en ambos grupos, le siguen las revistas (11\% y $28 \%$, respectivamente), tesis (24\% y $16 \%$, respectivamente ) y artículos (15\% y $13 \%$, respectivamente). 


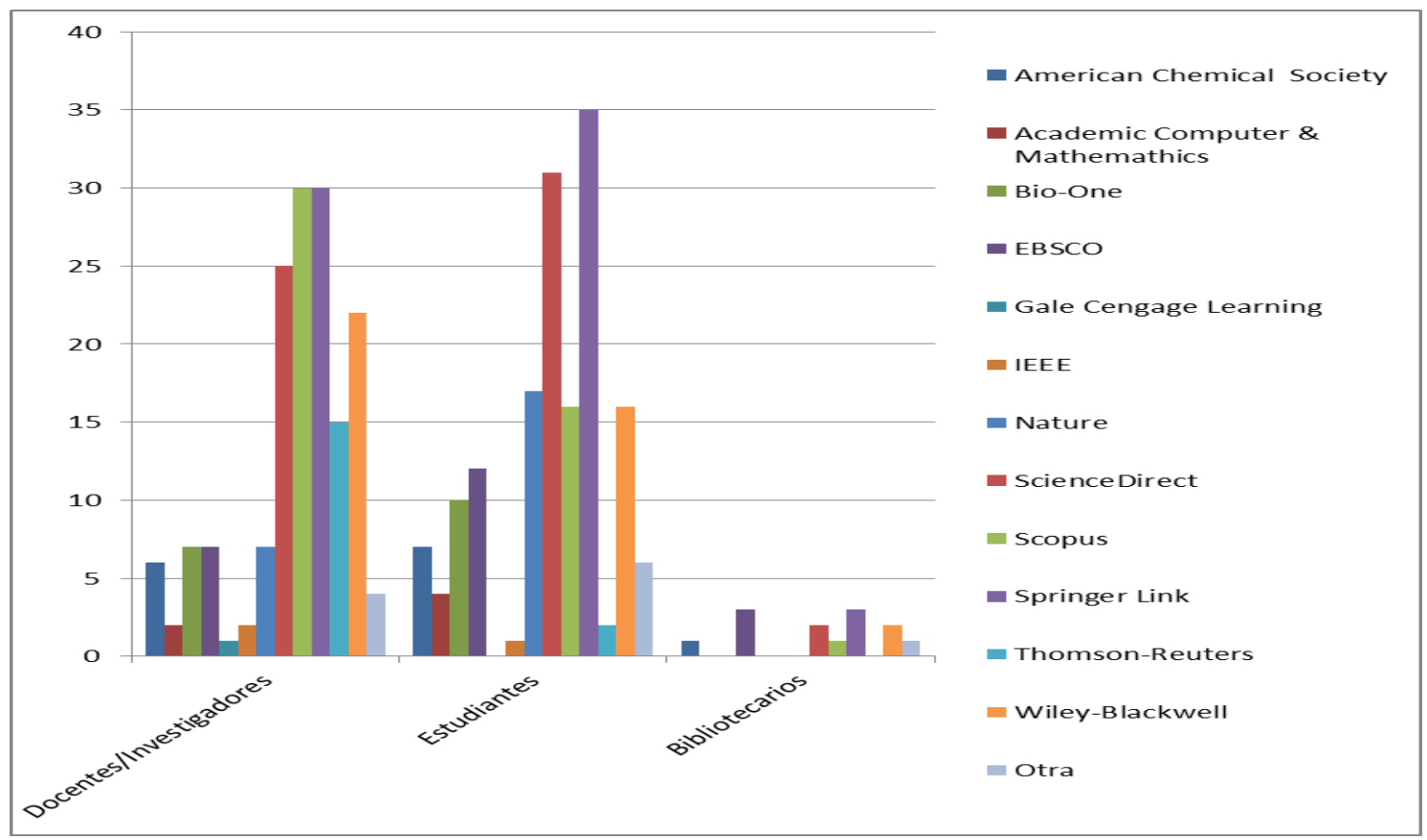

Figura 7. Base de Datos consultadas con más frecuencia

En la Fig. 7 se muestran las Bases de Datos que son más consultadas por la población encuestada. A Springer Link corresponde el valor más alto en los tres grupos (22\%, $19 \%$ y $23 \%)$, en segundo lugar Scopus en Docentes/Investigadores (19\%), Science Direct en Estudiantes (20\%), y EBSCO en Bibliotecarios (23\%). El tercer puesto lo ocupa Science Direct (16\%) en Docentes/Investigadores, Nature (11\%) en Estudiantes y Wiley-Blackwell como Science Direct respectivamente con (15\%) en Bibliotecarios.

\subsection{Dificultades en la búsqueda de información}

En la Fig. 8, el grupo de los Docentes/Investigadores indican que el problema que tiene el estudiante en la búsqueda, recuperación y uso de la información se debe en primer lugar en dificultad para sintetizar las ideas principales y realizar un nuevo producto o idea (17\%). En segundo lugar, el acceder a un excesivo volumen de información y no saber ajustarla a sus necesidades (15\%). En tercer lugar, dificultad para utilizar sistemas, técnicas y herramientas adecuadas de búsqueda de información tradicionales y electrónicas como catálogos, índices y bases de datos (15\%) y en cuarto desconoce cómo se produce, organiza y difunde la información (14\%) .

Los bibliotecarios coinciden con los Docentes/Investigadores en la dificultad para utilizar sistemas, técnicas y herramientas adecuadas de búsqueda de información tradicional y electrónicas como catálogos, índices, bases de datos (29\%) y acceder a un excesivo volumen de información y no saber ajustarla a sus necesidades (29\%).

También señalan que el estudiante confunde los diversos tipos de fuentes de información y formatos (28\%). 


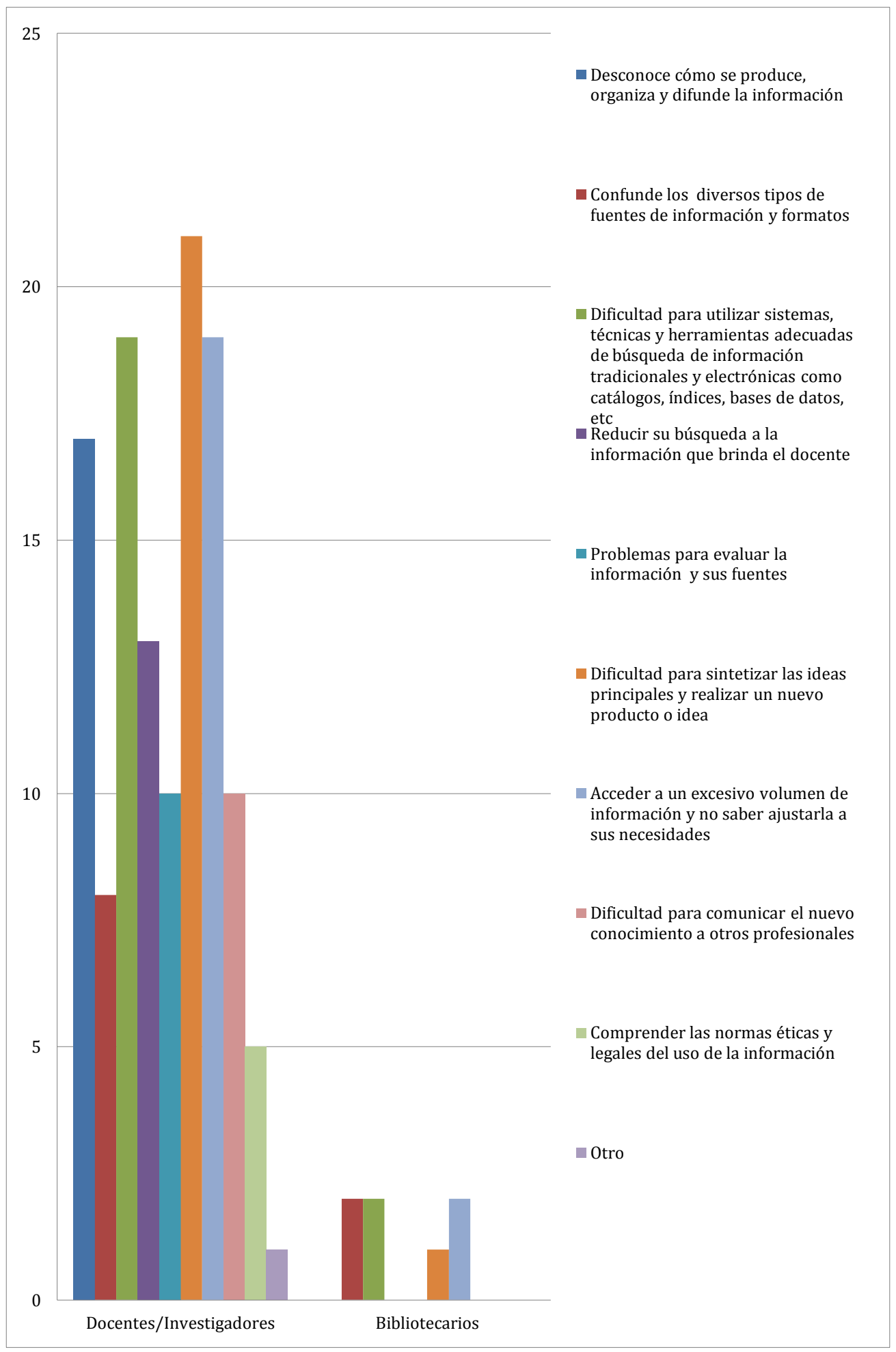

Figura 8. Dificultad de estudiantes en la búsqueda de información 


\subsection{Experiencia en bases de datos}

Los estudiantes expresan en la Fig. 9, que poseen amplio dominio para identificar la información mediante campos de autor, título y tema (25\%), pero el valor más bajo es para localizar información utilizando los operadores booleanos (10\%). En cambio los bibliotecarios si identifican información utilizando operadores booleanos (19\%).

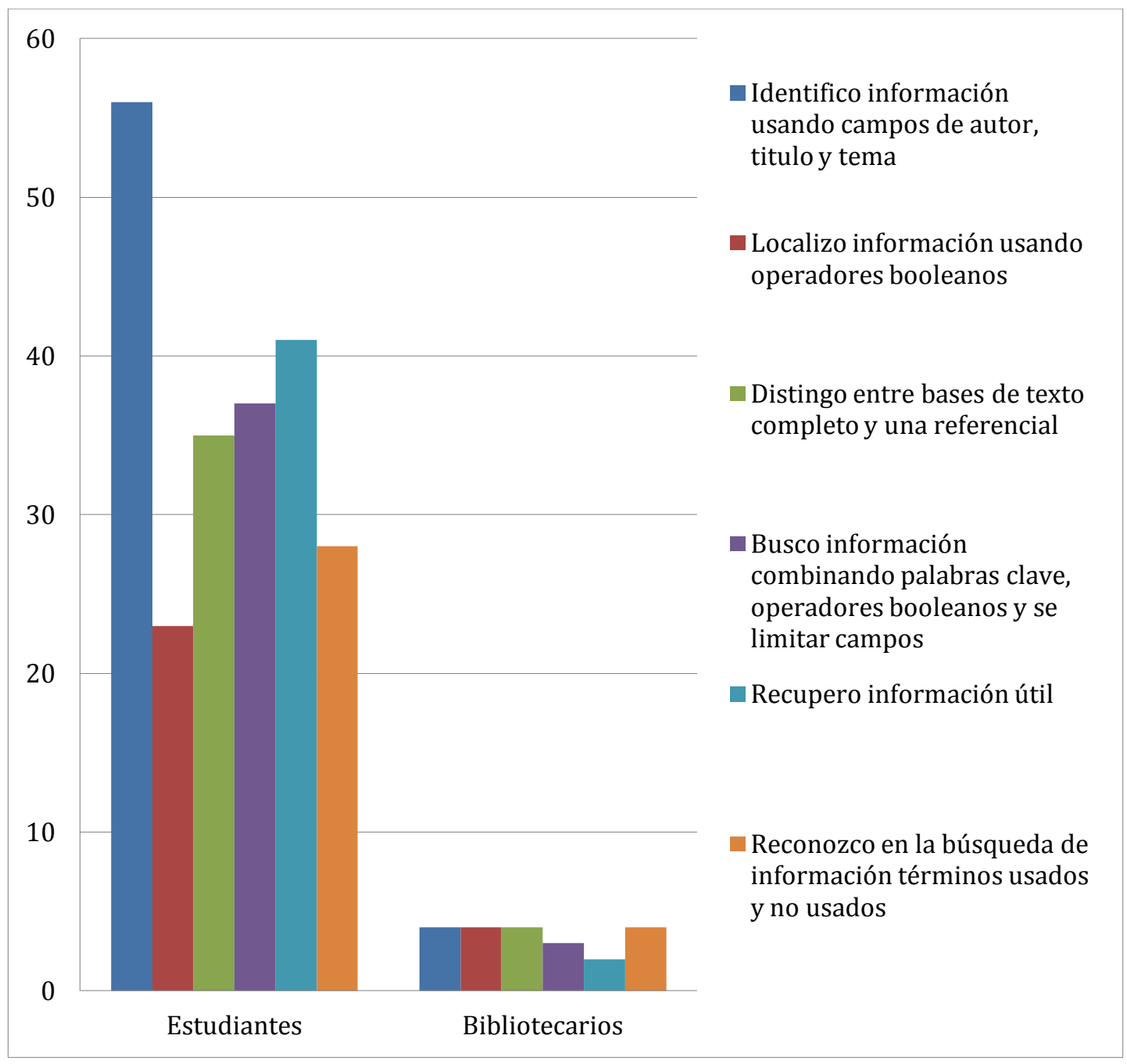

Figura 9. Experiencia en el uso de bases de datos

\subsection{Fomentar competencias informacionales}

De acuerdo a las respuestas expresadas en la Fig. 10, por los Docentes/Investigadores y los Bibliotecarios, sobre la forma de fomentar las competencias informacionales en los estudiantes, se registra el valor más alto en la modalidad de conferencia (26\% y 30\%, respectivamente); seguido por talleres de naturaleza optativa y de naturaleza propedéutica en los estudiantes de nuevo ingreso (23\% y $20 \%$, respectivamente); así como la formación individualizada en tercer sitio ( $16 \%$ y $10 \%$, respectivamente). 


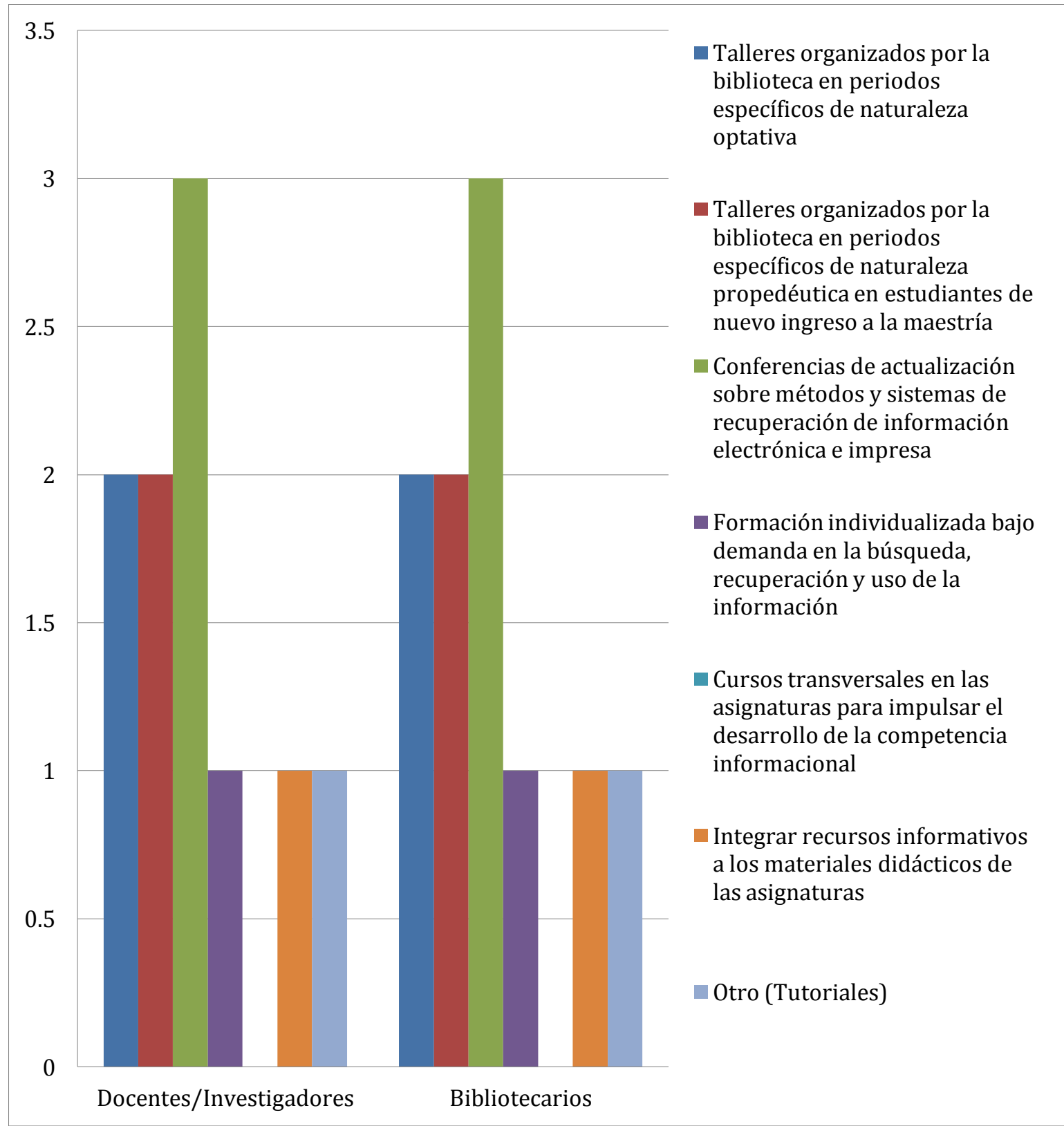

Figura 10. Propuestas para fomentar competencias informacionales 


\subsection{Conexión a Internet}

En la Fig. 11, se indica el número de horas que los tres grupos consideran ideales de conexión a Internet para mejorar su desempeño profesional o laboral. Se encontró una preferencia de más de diez horas (36\%, 31\% y 50\%) y de 4 a 6 horas (31\%, 37\% y 25\%) en los tres grupos respectivamente.

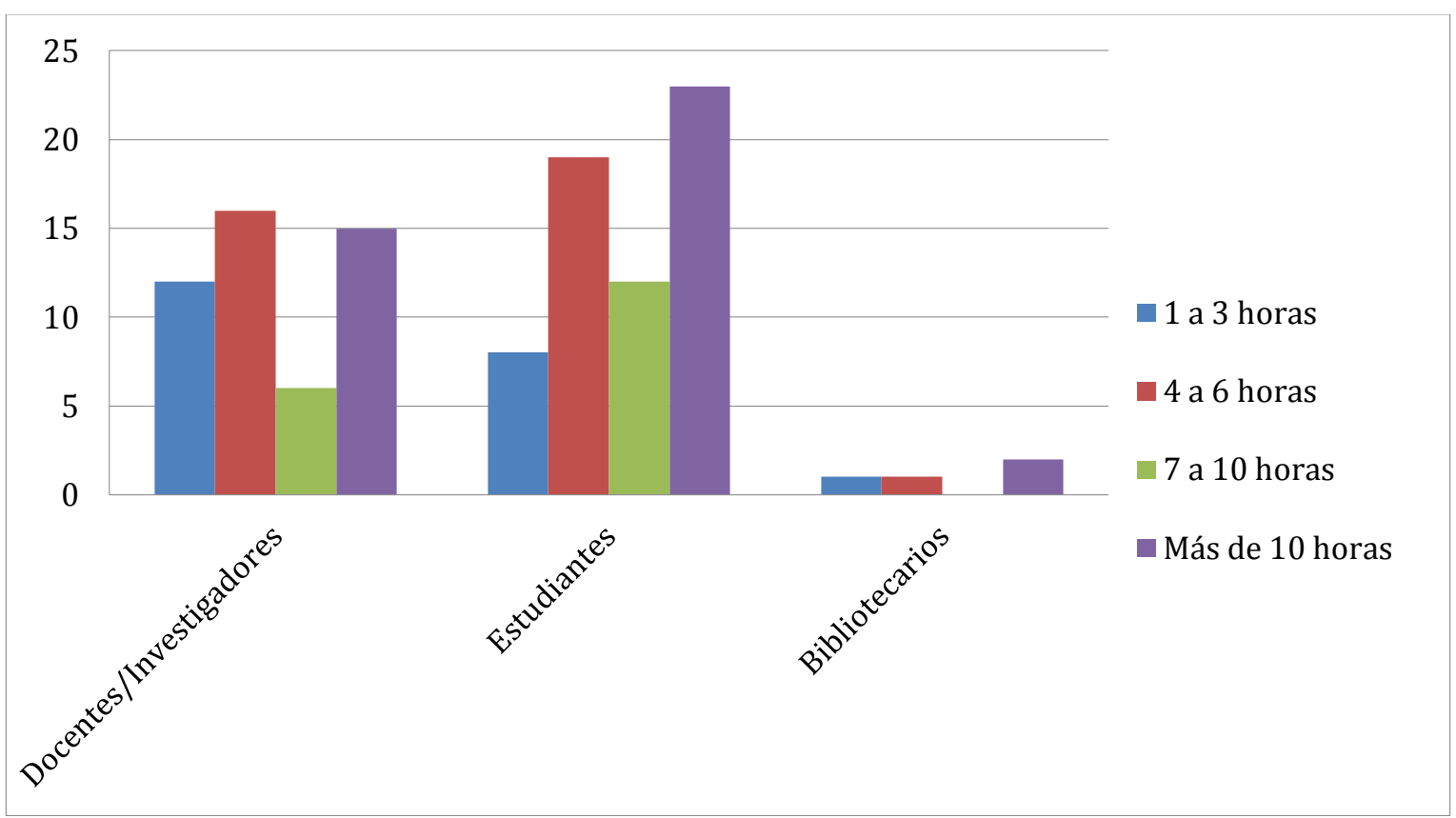

Figura 11. Horas de conexión a Internet

La Fig. 12, indica que en el grupo de Docentes/Investigadores predomina el interés investigativo (44\%) seguido del académico (38\%), el cultural-entretenimiento solo $(6 \%)$. En el caso de los Estudiantes, éstos se inclinan por lo académico (38\%) seguido de investigativo (35\%) y cultural-entretenimiento (20\%). La tendencia en los bibliotecarios es laboral (57\%), investigativo 29\% y cultural-entretenimiento $14 \%$.

En la Fig. 13, se ilustra las herramientas y servicios de Internet que aprovecha cada grupo de encuestados durante la semana. Sobresale en los tres grupos el uso del correo electrónico (38\%, 33\% y $45 \%)$ y las Bases de datos (26\%, $22 \%$ y $44 \%$ respectivamente). Los Docentes/Investigadores y los Estudiantes señalan el uso del Chat (8\%). Son los Estudiantes lo que más hacen uso de Videos (9\%) y Audios en línea (8\%). Y Bibliotecarios la lista de correo (11\%). El resto de los servicios quedan por debajo de un valor de (8\%) que respondieron que lo usan. 


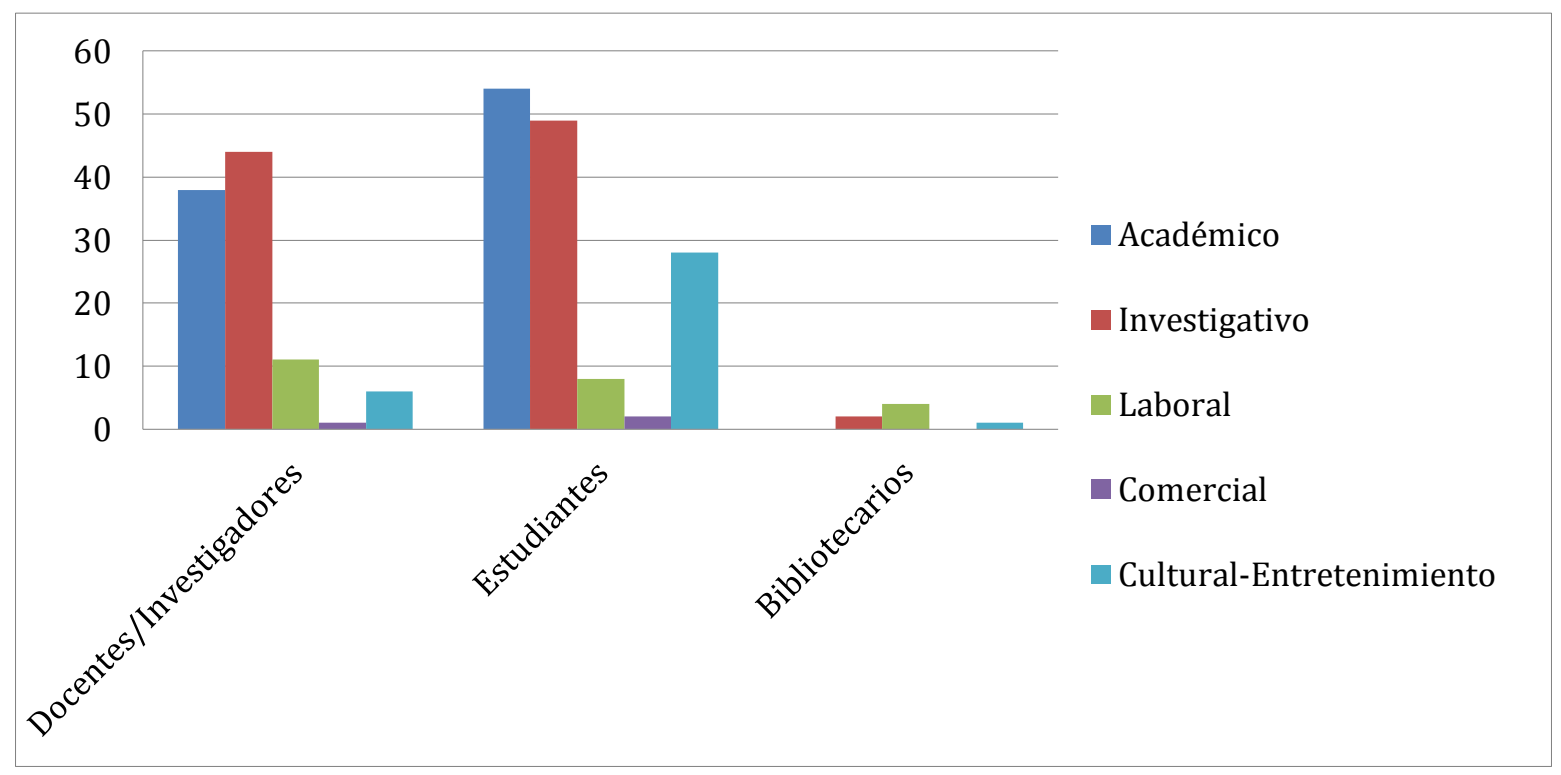

Figura 12. Motivaciones para acceder a Internet

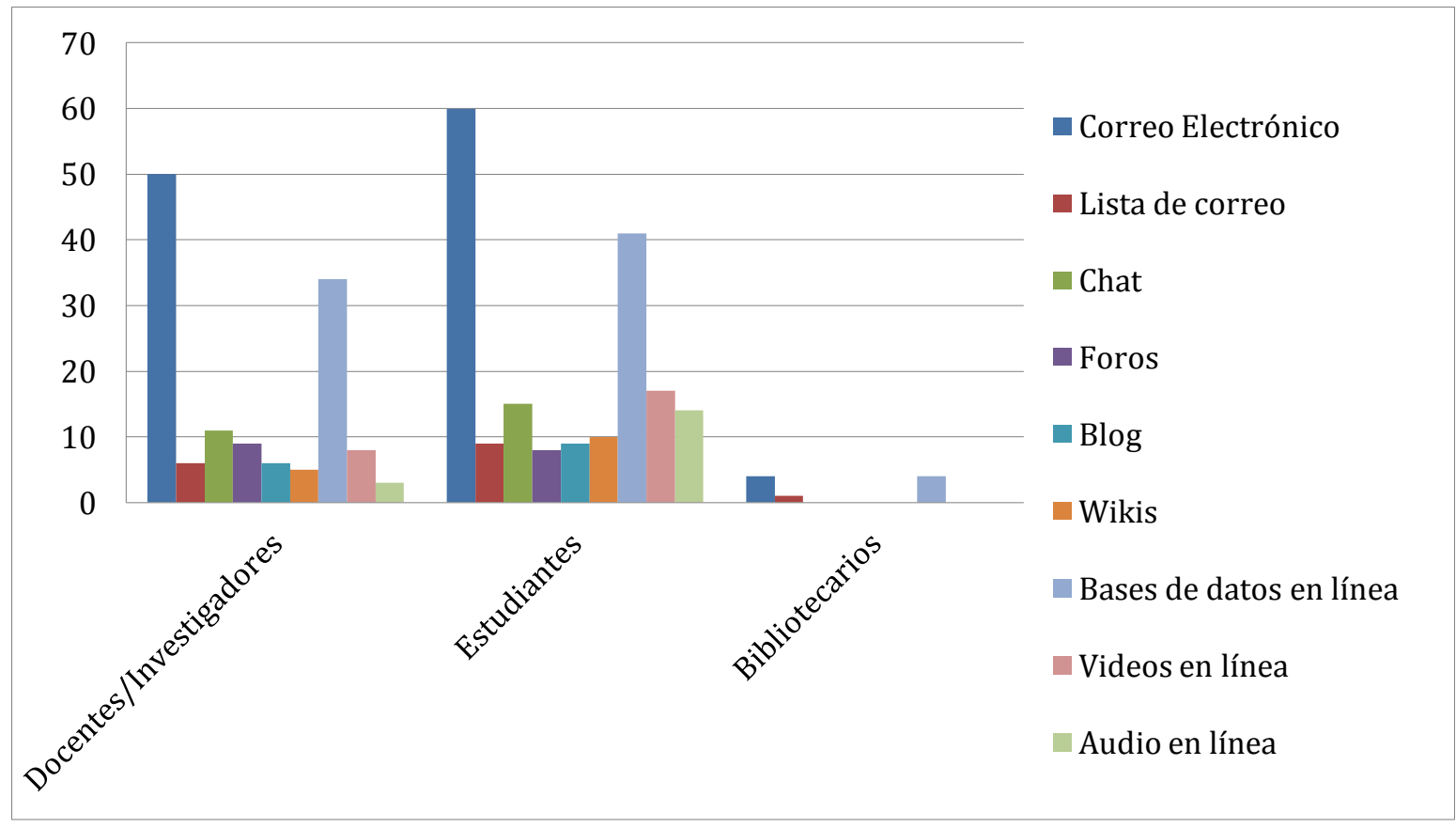

Figura 13. Herramientas y Servicios de Internet empleados 


\section{Discusión}

\subsection{Gestión de la Información}

Los resultados encontrados en las encuestas afirman que la información institucional es muy útil en los tres grupos de encuestados, pero también lo poco efectivo de la comunicación, hecho que indica que la interacción entre información y comunicación, no corresponde a un sistema de información adecuado a las exigencias de la comunidad encuestada. Es decir, no existe como afirma Chaín Navarro (1999), la noción integradora de organización como un sistema informativo, dónde la tarea de optimizar recursos a través de un adecuado análisis de las necesidades de información contribuya a que la organización o sus usuarios puedan alcanzar sus metas.

\subsection{Servicios bibliotecarios}

Por otra parte, al examinar el comportamiento de Docentes/Investigadores y Estudiantes, con relación a los servicios, se manifiesta una diminuta demanda en el Préstamo Interbibliotecario y en la Instrucción de Usuarios, a pesar de contar con una Credencial Única de Préstamo Interbibliotecario. El bajo aprovechamiento de este servicio, quizás tenga origen en que la bibliografía incorporada en los programas de las asignaturas no están actualizados 0 que los bibliotecarios no han promovido correctamente los recursos y servicios producto de la cooperación interbibliotecaria.

En el servicio de Instrucción de Usuarios, no se ha logrado establecer una estrategia conveniente para fomentar el aprovechamiento de las colecciones y servicios que ofrece la biblioteca. No obstante, que desde el año 2000, el personal de la biblioteca organiza una reunión de bienvenida semestral para los alumnos de nuevo ingreso con dos propósitos: uno que el estudiante se familiarice con los servicios bibliotecarios y recursos informativos disponibles en la biblioteca; y el otro que identifiquen al personal de la biblioteca y las actividades que éste realiza, para que soliciten y reciban el apoyo adecuado de dicho personal.

\subsection{Tecnologías de información y comunicación (TIC)}

El desmesurado crecimiento de información en el contexto actual en la sociedad, demanda la autonomía de los usuarios en los procesos de apropiación, generación y distribución de la información.

Con esa lógica, en cuanto a accesibilidad y conectividad el CICIMAR-IPN asume políticas positivas con respecto al uso de las TIC. Toda la comunidad tiene acceso a la infraestructura informacional: Internet, Intranet, Computadoras y Software. No obstante, el ancho de banda es insuficiente y esto provoca que los nuevos desarrollos virtuales orientados a la educación se desarrollen con lentitud.

A pesar de lo antes señalado, el número de horas que se mantienen conectado los usuarios a la Red, oscila de entre seis y más de diez horas diarias, en tanto que su interés es consecuente a las actividades que realizan. Con respecto al uso de las TIC con fines culturales y de entretenimiento son los estudiantes, quienes expresan una afición mayor, si se estima que es una población joven (20-30 años), familiarizada con las herramientas TIC. De ahí que, sean ellos quienes aprovechan los videos y música en línea, en cuanto a las herramientas y servicios de Internet, pero es contradictorio la poca utilidad de los Blogs, Foros y Wikis, cuyo beneficio consiste en difundir ideas para generar redes de aprendizaje.

En lo que se refiere al aprovechamiento de las herramientas y servicios de Internet, la preferencia en los tres grupos de encuestados es el Correo Electrónico y las Bases de Datos, la posible ponderación del primero está orientado en la facilidad de uso y la posibilidad de comunicar e intercambiar información. En el caso de las Bases de Datos, su notoriedad reside probablemente en la amplia cobertura sobre diversidad de publicaciones fundamentales para la biología marina, pesquerías, oceanografía y temas afines.

Sin embargo, al observar la declaración de Docentes/Investigadores y Bibliotecarios, sobre el excesivo volumen de información que recuperan los Estudiantes y que no saben ajustarla a sus necesidades de información y tienen un conocimiento limitado en los diversos tipos de fuentes de información, se evidencia de que se requiere una formación dirigida al aprovechamiento de las TIC, aunado a la resistencia de Docentes/Investigadores de aprender nuevas formas de aprender y la consecuente falta de apropiación de las TIC. 


\subsection{Competencias informacionales}

A decir de Marciales Vivas et al. (2008), las competencias informacionales se interpretan como un entramado entre las adhesiones y creencias, las motivaciones y las aptitudes del sujeto, construidas a lo largo de su historia en contextos situados de aprendizaje, formales y no formales.

Así, respecto a las necesidades de información, la opinión generalizada de mayor importancia se concede a la definición de dicha necesidad, sin embargo restan importancia a identificar la variedad de tipos y fuentes potenciales de información, junto con modificar el nivel de información que necesita.

Los resultados obtenidos en este rubro, indican que los Docentes/Investigadores saben de antemano que sistemas pueden brindarle la información que están requiriendo y en cambio los Estudiantes no tienen claro que sistema puede servirles y por esa razón primero extraen lo que suponen necesitan. El tema no es pronunciarse por quien ejecuta el proceso ordenadamente, sino más bien es destacar que las habilidades tecnológicas de los Estudiantes los conduce a ignorar o dar por asentado que la información la localizarán indistintamente del sistema de información de donde provenga. Sin embargo, la "navegación" estructurada y asociativa e hipertextual de los sistemas actuales no es suficiente para desconocer los principios básicos que dan valor y crédito a la información. En otras palabras, Docentes/investigadores y Bibliotecarios deben fomentar dichos conocimientos a la vez que transforman sus propios conocimientos acercándose a las tecnologías y alejándose de la estructura jerárquica y lineal del texto, para que el aprendizaje sea un acto recíproco.

En la aptitud para evaluar la información se encuentran prácticas en concordancia con sus perfiles profesionales. Los Docentes/Investigadores por su formación de expertos sobre áreas de conocimiento de su especialidad, poseen características propias que aprovechan para evaluar la información y se centran en extraer las ideas principales de la información, sintetizar las ideas para construir nuevos conceptos, comprender e interpretarlos por medio de un intercambio de opinión.

Las características distintivas que conducen a los Estudiantes además de evaluar la información centrándose en resumir las ideas principales como a los Docentes/Investigadores, a comparar los nuevos conocimientos con los anteriores y comprender e interpretar la información por medio del intercambio de opinión, para finalmente construir nuevos conceptos, indica que no dominan el área de conocimiento y que hay un proceso de aprendizaje, por eso comparan los nuevos conocimientos con los anteriores.

En el caso de los Bibliotecarios, ellos se inclinan en evaluar la información y sus fuentes, su interés encaja con la formación técnica que los distingue, sintetizar las ideas principales para construir nuevos conceptos y compararlos para identificar otras características únicas de la información y finalmente comprenderla e interpretarla.

Al respecto de la aptitud para utilizar la información, tanto Docentes/Investigadores y Estudiantes comparten opinión de aplicar la información recién adquirida a la anterior para crear un nuevo producto, comunicarla y reconocer las fuentes de información en el producto a comunicar. Sin embargo, los resultados alertan sobre la tendencia a restar importancia a comprender las cuestiones éticas, legales y sociales que implican a la información y a las TIC, así como atender las reglas y políticas institucionales y normas de cortesía a la hora de comunicar el producto o actividad que se realiza.

En cuanto a la aptitud de mejorar los conocimientos y habilidades en la búsqueda, recuperación y uso de la información, la disponibilidad de todos los encuestados es notoria al aceptar aprender nuevos contenidos. Mediante conferencias, talleres de naturaleza optativa y de naturaleza propedéutica en los estudiantes de nuevo ingreso. Además que las opiniones sobre los cursos virtuales son positivas.

Para finalizar, no hay que perder de vista que los juicios antes descritos son de gran utilidad para guiar las acciones ALFIN que se inicien, pero no lo son todo y en la medida que se pongan a prueba y se evalúen se podrán definir mejor. 


\section{Conclusiones}

El estudio concluyó que los componentes Docentes/Investigadores, Estudiantes y Bibliotecarios del CICIMAR-IPN representados en esta muestra, en general dominan algunas de las competencias definidas en los perfiles específicos a cada sector, no obstante se precisa atender algunos componentes referidos en dichos perfiles, evidenciados en la presente investigación y que pueden ser abordados desde la perspectiva de ALFIN, para fomentar el aprendizaje a lo largo de la vida.

De otro lado el componente Docentes/Investigadores del CICIMAR-IPN requiere ser capacitado en el uso de las TIC y el reconocimiento de las normas de propiedad intelectual en los ambientes virtuales. En el caso del componente de los Estudiantes del CICIMAR-IPN, es necesario fomentar el aprendizaje de las competencias informacionales, a través del impulso tanto de conocimientos técnicos como valores para reconocer las normas de propiedad intelectual. Así también el componente de los Bibliotecarios del CICIMAR-IPN precisa del desarrollo competencias directivas y pedagógicas que les permitan transmitir los conocimientos que poseen.

Por lo anterior se sugiere establecer un Plan de Alfabetización Informacional dentro del marco institucional del Instituto Politécnico Nacional, que permita fomentar las competencias informacionales en la comunidad académica del CICIMAR-IPN y lograr la sensibilización de dicha comunidad.

El plan de acciones debería incluir actividades como:

- Sensibilizar a la comunidad del CICIMAR-IPN bajo la propuesta de ALFIN.

- Incluir en la página web de la biblioteca un apartado de ALFIN, que contenga la promoción de los talleres, conferencias y nuevos servicios.

- Distribuir mensajes electrónicos personalizados con invitación para las conferencias sobre comunicación y redes del conocimiento científico que se organicen.

- Rediseñar los trípticos y separadores promocionales de los servicios con frases alusivas a ALFIN.

- Fomentar las competencias informacionales en el componente de Estudiantes: Taller en Gestión de Información y Comunicación Científica.

- Fomentar las competencias informacionales en el componente de Bibliotecarios: Taller en Competencias Informativas y Científicas.

- Fomentar las competencias informacionales en el componente de Docentes/Investigadores y Bibliotecarios: Ciclo de conferencias "Comunicación y Redes del Conocimiento Científico".

\section{Bibliografía}

Chaín Navarro, C. (1999). Gestión de información para la investigación. Desarrollo y consolidación de las funciones del gestor como asesor y consultor para la ciencia y la tecnología. Ciencias de la Información, 30(4), 41-60.

Lau, J. (2004). Directrices Internacionales para la Alfabetización Informativa (Propuesta): Sección de Alfabetización Informativa de IFLA.

Marciales Vivas, G. P., González-Niño, L., Castañeda-Peña, H. \& Barbosa-Chacón, J.W. (2008). Competencias informacionales en estudiantes universitarios: una reconceptualización. Universitas Psychologica, 7(3), 643-654.

Núñez Paula, I. (2004). AMIGA: una metodología integral para la determinación y la satisfacción dinámica de las necesidades de formación e información en las organizaciones y comunidades. ACIMED, 12(4), 29. 
Uribe Tirado, A., Ramírez Marín, G. J., Arroyave Palacio, M. M., Pineda Gaviria, M., Valderrama Muñoz, A. M. \& Fernando Preciado, J. (2008). Acceso, conocimiento y uso de Internet en la universidad. Modelo de diagnóstico y caracterización: Caso Universidad de Antioquía. Medellín: Universidad de Antioquia/EIB-CICINF.

Valdés Cuervo, A. A., Vera Noriega, J. A., \& Carlos Martínez, E. A. (2012). Competencias científicas en estudiantes de posgrado de ciencias naturales e ingenierías. Sinéctica. Revista Electrónica de Educación (39). Disponible en: http://www. sinectica. iteso.mx.

\section{Datos de los autores}

\section{Teresa de Jesús Barriga Ramírez}

Maestra en Gestión de Información por la Universidad de La Habana, profesora-investigadora del Instituto Politécnico Nacional, coordinadora de los Servicios Bibliotecarios en la Biblioteca "Reuben Lasker" del Centro Interdisciplinario de Ciencias Marinas del I.P.N. (CICIMAR-IPN). Experiencia como instructora de cursos de capacitación y actualización bibliotecaria.

tbarriga@ipn.mx

\section{José Luis Ortíz Galindo}

Doctor en Ciencias Biológicas por la Facultad de Ciencias de la UNAM, profesor-investigador del Instituto Politécnico Nacional, director de tesis de posgrado y de proyectos de investigación en el área de las Ciencias Marinas.

jortizgalindo@gmail.com

\section{Laura Margarita Pérez Rojas}

Ingeniero en Sistemas Computacionales, profesora-investigadora del Instituto Politécnico Nacional, responsable de la Unidad de Tecnología Educativa y Campus Virtual del CICIMAR-IPN, con diplomado de formación y actualización docente y ha realizado varios software de aplicación en el control de información digital. lperezr@ipn.mx

\section{Bárbara Susana Sánchez Vignau}

Doctora en Ciencias de la Información por la Universidad de La Habana, profesora-investigadora de la Universidad de La Habana, directora de tesis de posgrado en los temas de bibliotecas virtuales, evaluación de servicios de información, diseño de repositorios de información y estrategias de aprendizaje organizacional. susan@dict.uh.cu

Recebido - Received : 2014-04-09

Aceitado - Accepted : 2014-09-30

\section{$(c)$ EY}

This work is licensed under a Creative Commons Attribution 4.0

United States License.

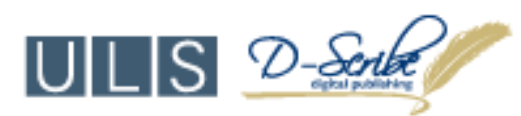

This journal is published by the University Library System of the University of Pittsburgh as part of its D-Scribe Digital Publishing Program and is cosponsored by the University of Pittsburgh Press. 